\title{
STATUS OF EARLY MORTALITY IN NEWLY DIAGNOSED CASES OF ACUTE PROMYELOCYTIC LEUKAEMIA (APL) IN BSMMU HOSPITAL
}

\author{
RAHMAN $F^{1}$, YUNUS ABM $^{2}$, KABIR AL $^{3}$, BEGUM M $^{4}$, AZIZ A ${ }^{3}$, SHAH S $^{3}$, RAHMAN F ${ }^{5}$, RAHMAN MJ $^{6}$
}

\begin{abstract}
:
Background: Acute promyelocytic leukemia (APL), is now curable in most cases with current treatment strategies. But limited available data suggest that the rate of early mortality is high and long term survival is poor in many developing countries. To improve the survival rate by reducing early mortality, study of the status of early mortality as the main cause of treatment failure for the management of APL as a heamatological emergency appears to have a great significance.
\end{abstract}

Materials and method: Diagnosis of acute promyelocytic leukemia was done from bone marrow morphological study by experienced haematologist. After that cytogenetic study to see chromosomal translocation 15 and 17 and molecular study to see PML-RARá fusion protein was also done. Clinical and laboratory evaluation was done to all of them. Chemotherapy according to IC-APL protocol was given to 30 out of 40 patients. Incidence of early mortality (death within 14 days of diagnosis) was recorded and also categorized according to cause of death. Pattern of supportive cares given to the patients such as management of coagulopathy. ATRA syndrome or sepsis to treat the disease as a medical emergency was also recorded.

Result: Selected clinical, laboratory and outcome data of 40 cases of APL who were admitted in Haematology department of BSMMU was surveyed. The median age overall was 32 yrs. The median WBC count at diagnosis was $7.75 \times 10^{9} / \mathrm{L}$ and median platelet count $25 \times 10^{9} / \mathrm{L}$. Laboratory evidence of DIC was noted in $37.5 \%$ of patients. Death occurred within 14 days of diagnosis (early death) in 10 (25\%) cases. Bleeding was the most common cause of early death, then infectious complication and ATRA syndrome. Among 30 patients who got chemotherapy complete remission (CR) was 66.6\%. So only 50\% of the total study population was able to achieve CR. So due to early mortality, a significant portion of the study population could not receive protocol based treatment.

Conclusion: To improve outcome by reducing initial mortality early recognition and treatment of APL is required in specialized institutions, by prompt and aggressive supportive therapy as well as immidiate starting of antileukemic agent such as ATRA, arsenic trioxide etc.

Key words: Acute Promyelocytic Leukaemia (APL), mortality.

J Dhaka Med Coll. 2009; 18(2) : 150-154

\section{Introduction:}

Acute promyelocytic leukemia (APL) with $\mathrm{t}(15,17)(\mathrm{q} 22 ; \mathrm{q} 12)$ is type of acute myeloid leukemia in which abnormal promyelocytes predominate. ${ }^{1}$ In the past 15 years an extraordinary combination of laboratory and clinical research studies have in fact contributed to transform this once rapidly fatal disease into the most frequently curable adult leukemia. ${ }^{2,3}$ Introduction of all-trans-retinoic acid (ATRA) in initial therapy of acute promyelocytic (APL) represents one of the most spectacular advances in the treatment of human cancer. ${ }^{4}$ However APL is now curable in most cases with current treatment strategies, these strategies may be unavailable in countries with limited resourses. ${ }^{5}$ There are other aspects of APL management that are relevant to the outcome in individual patients. These are appropriate diagnostic tools and strategies, supportive care, recognition and treatment of life threatening complications,

1. Medical Officer, Department of Haematology, BSMMU, Dhaka.

2. Professor, Department of Haematology, BSMMU, Dhaka.

3. Assistant Professor, Department of Haematology, BSMMU, Dhaka.

4. Associate Professor, Department of Haematology, BSMMU, Dhaka.

5. Medical Officer, Department of Medicine, BSMMU, Dhaka.

6. Professor \& Chairman, Department of Haematology, BSMMU, Dhaka.

Correspondence: Dr. Farzana Rahaman. 
evaluation of response etc. ${ }^{6,7} \mathrm{APL}$ is particularly associated with major coagulation disturbance resulting fatal haemorrhage in $20 \%$ of patient during the presentation period. ${ }^{2,8}$ The limited available data suggest that, the rate of early mortality is high and longterm survival is poor in many developing countries. ${ }^{5}$ To facilitate the development of local capacity and implement effective treatment for APL in developing countries, study of early mortality in newly diagnosed cases of acute Promyelocytic leukemia and its impact on the treatment outcome appears to have a great significance. 5,7

\section{Materials and Methods:}

Between July 2006 and June 2009, 40 patients were diagnosed morphologically from bone marrow examination by experienced haematologist, to have APL. After that cytogenetic study to see chromosomal translocation of 15 and 17 and molecular study to see PML-RARá fusion protein was also done. Clinical and laboratory evaluation was done to all of them. Slandard demographic data was also recorded. Chemotherapy according to ICAPL protocol was given to 30 out of 40 patients as 7 patient died before starting chemotherapy and 3 patient refused to take chemotherapy because of financial problem. All-transretinoic acid (ATRA) was initiated after admission in haematology dept. after sending the bone marrow sample to confirm the diagnosis. Incidence of early mortality was recorded and also categorized according to cause of death. Pattern of supportive cares given to the patients as to manage the disease as a medical emergency was also recorded. The term complete remission means the bone marrow is regenerating normal haemopoietic cells and contains $<5 \%$ leukemic cells (as recognized by blast morphology or by relevant cytogenetic markers) ${ }^{9}$.The study was done in Haematology department of Bangabandhu Sheikh Mujib Medical University, Dhaka. After meticulous checking and rechecking data was entered into the computer and appropriate statistical analysis was done with
SPSS 17.0 programme. Informed consent was obtained in accordance with the Declaration of Helsinki.

\section{Results and Observations:}

The present study was conducted on 40 newly diagnosed cases of Acute Promyelocytic Leukaemia (APL) to study clinical features, selected laboratory data, incidence and cause of early mortality. Demographic data shows that $30 \%$ of the patients was in the range of $31-40$ years of age, followed by $27.5 \%$ between 21 - 30 years, $22.5 \%$ above 40 years and the remaining $20 \% 20$ or below 20 years of age. The median age was 32 years and the minimum and maximum ages were 12 and 52 years respectively. Almost two-third (65\%) of the patients was male giving a male to female ratio of roughly $2: 1$. clinical data reveals that over three-quarter $(77 \%)$ of the patients had fever at presentation and the rest 23\% did not. More than three quarter $(77.5 \%)$ of the patients exhibited evidence of bleeding under skin and mucous membrane, $32.5 \%$ had gastrointestinal tract bleeding, $17.5 \%$ pulmonary bleeding, $15 \%$ intramuscular and $17.5 \%$ intracranial bleeding (Table I).Hematological profile demonstrates that the median haemoglobin level was 9.0 $\mathrm{gm} / \mathrm{dl}$ and the lowest and highest levels were 3 and $11.5 \mathrm{gm} / \mathrm{dl}$. The median white blood cell (WBC) count was $7.75 \times 109 / \mathrm{L}$ and median platelet count was 25.0 X 109/L(Table II).

Table-I

Distribution of patients by site of bleeding $(n=40 *)$

\begin{tabular}{lcc}
\hline Site of bleeding & Frequency & Percentage \\
\hline Skin and mucous & 31 & 77.5 \\
membrane & & \\
Gastrointestinal & 13 & 32.5 \\
Pulmonary & 07 & 17.5 \\
Intramuscular & 06 & 15.0 \\
Intracranial & 07 & 17.5 \\
\hline
\end{tabular}

* Total will not correspond to $100 \%$, because of multiple response 
Table-II

Distribution of patients by hematological profile $(n=40)$

\begin{tabular}{|c|c|c|}
\hline $\begin{array}{l}\text { Laboratory } \\
\text { investigations }\end{array}$ & Mean & Range \\
\hline $\mathrm{Hb}(\mathrm{gm} / \mathrm{dl})$ & 9.0 & $3-11.5$ \\
\hline $\begin{array}{l}\text { Total count of WBC } \\
\text { (/L of blood) }\end{array}$ & $7.75 \times 10^{9}$ & $(0.5-250) \times 10^{9}$ \\
\hline $\begin{array}{l}\text { Platelet count } \\
\text { (/L of blood) }\end{array}$ & $25.0 \times 10^{9}$ & $(6-180) \times 10^{9}$ \\
\hline
\end{tabular}

Other laboratory investigations reveals liver function test was noted abnormal in $3(7.5 \%)$ cases and raised serum creatinine level in $2(5 \%)$ cases. APTT prolonged, PT prolonged and D-Dimer increased each found in $15(37.5 \%)$ cases. Fibrinogen level decreased 12(30\%) cases. Majority of patients (92.3\%) are characterized by the presence of karyotype $\mathrm{t}(15 ; 17)$. Fifteen $(37.5 \%)$ cases had disseminated intravascular coagulation (DIC) at presentation (Table III). Over three quarter $(77.5 \%)$ of the patients received $\mathrm{RCC}$ transfusion for correction of anaemia, 57.5\% received platelet concentrate transfusion. Seventy percent were given management of infection and sepsis, 30\% management of DIC and $12.5 \%$ management of ATRA syndrome (Table IV).

Table-III

Distribution of patients by selected laboratory data $(n=40)$

\begin{tabular}{llc}
\hline $\begin{array}{l}\text { Laboratory } \\
\text { investigations }\end{array}$ & Frequency & Percentage \\
\hline Liver function test (Abnormal) & 03 & 7.5 \\
S. creatinine level (Raised) & 02 & 5.0 \\
APTT (Prolonged) & 15 & 37.5 \\
PT (Prolonged) & 15 & 37.5 \\
D-Dimer (Increased) & 15 & 37.5 \\
Fibrinogen level (Decreased) & 12 & 30.0 \\
Karyotype & & \\
t(15,17) & 24 & 92.3 \\
Not t(15,17) & 02 & 7.7 \\
DIC at presentation & 15 & 37.5 \\
\hline
\end{tabular}

Table IV

Distribution of patients by type of treatment $(n=40 *)$

\begin{tabular}{lcc}
\hline Type of treatment & Frequency & Percentage \\
\hline $\begin{array}{l}\text { RCC transfusion for } \\
\text { correction of anaemia }\end{array}$ & 31 & 77.5 \\
$\begin{array}{l}\text { Platelet concentrate } \\
\text { transfusion }\end{array}$ & 23 & 57.5 \\
$\begin{array}{l}\text { Management of infection } \\
\text { and sepsis }\end{array}$ & 28 & 70.0 \\
$\begin{array}{l}\text { Management of DIC } \\
\text { Management of ATRA }\end{array}$ & 12 & 30.0 \\
syndrome & 05 & 12.5 \\
\hline
\end{tabular}

* Total will not correspond to $100 \%$, because of multiple response

Among the total study population three-quarter $(75 \%)$ of the patients received protocol based treatment and the remaining $25 \%$ only supportive therapy. 10 patient $(25 \%$ of total population)

could not receive protocol based treatment as 7 patients died before starting treatment and 3 patients abandoned the treatment. Outcome of specific treatment (Table V) shows that about two-third $(66.6 \%)$ of the patients entered remission, $10.3 \%$ died early, $16.2 \%$ did not respond (resistant disease), two $(6.9 \%)$ patients abandoned treatment.

\section{Table-V}

Distribution of patients by outcome of specific treatment $(n=30)$

\begin{tabular}{lcc}
\hline Outcome & Frequency & Percentage \\
\hline Remission & 19 & 66.6 \\
Early death & 03 & 10.3 \\
Resistant disease & 05 & 16.2 \\
Abandonment & 02 & 6.9 \\
\hline
\end{tabular}

Of the 40 patients, early mortality occurs among 10 patients that is $25 \%$ of the population (fig. 1). Seven of them (70\%) died at the time of getting only supportive care and rest $3(30 \%)$ died within the 14 days of starting chemotherapy (Table VI). So $17.5 \%$ of study population died before starting chemotherapy, immediately after admission. Bleeding was the most common cause of early death $(60 \%$ of the total mortality) and then ATRA syndrome and infectious complication each was 20\% (Table VII). Of the 40 patients $6(15 \%$ of total) died of bleeding (Fig. 5). 
So higher early mortality was the main cause of treatment failure in the study and bleeding was the main cause of early mortality and death due to bleeding accounts for the $15 \%$ of the total study population.

\section{Table VI}

Distribution of patients by mortality $(n=10)$

Category $\quad$ Frequency Percentage

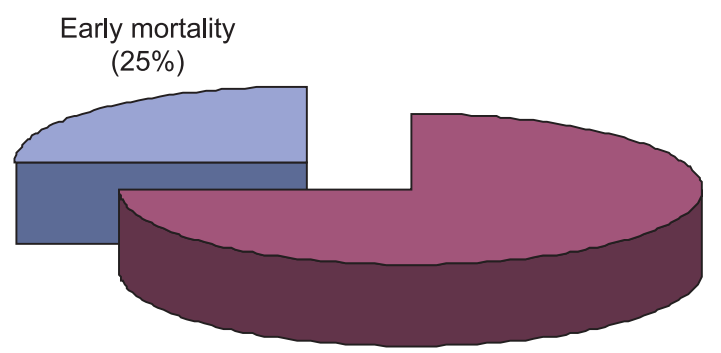

Fig.-1: Early mortality occurs among 25\% of the total study population.

\begin{tabular}{lcc}
$\begin{array}{l}\text { Mortality before } \\
\text { getting protocol } \\
\text { based treatment }\end{array}$ & 07 & 70.0 \\
$\begin{array}{l}\text { Mortality at the time } \\
\text { of specific treatment }\end{array}$ & 03 & 30.0 \\
\hline
\end{tabular}

Table-VII

Distribution of patients by cause of death $(n=10)$

\begin{tabular}{lcc}
\hline Outcome & Frequency & Percentage \\
\hline Bleeding & 06 & 60.0 \\
ATRA syndrome & 02 & 20.0 \\
Infectious complication & 02 & 20.0 \\
\hline
\end{tabular}

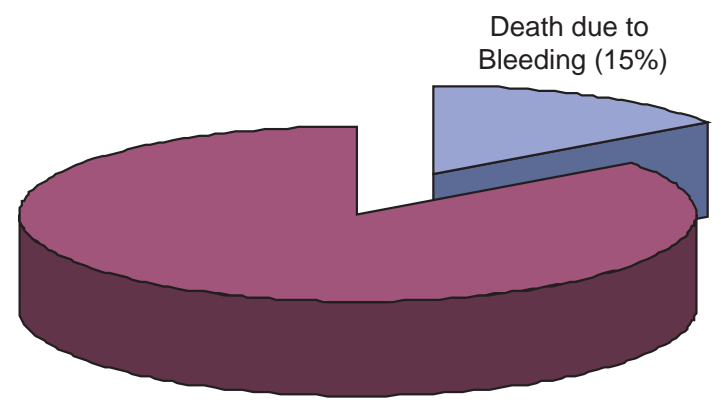

Fig.-2: Mortality caused by bleeding among the total patients $(n=40)$

\section{Discussion:}

Recently, a number of exhaustive reviews have been published on the treatment progress achieved in acute promyelocytic leukemia (APL), representing one of the most spectacular advances in the treatment of human cancer. ${ }^{7,10}$ However, these have focused mainly on the comparison of therapeutic approaches, including all-trans retinoic acid (ATRA) and chemotherapy, without much attention given to several important, apparently "minor" diagnostic and therapeutic aspects that could have crucial importance in patient outcome. ${ }^{7}$ In our study selected clinical, laboratory and outcome data for 40 APL patients showed that median age of presentation is $32 \mathrm{yrs}$. So more productive lives can be saved by curing this disease. Out of 40 patients, $77.5 \%$ patient got red cell concentration transfusion for correction of anaemia. $70 \%$ patient got management of infection and sepsis. $57.5 \%$ patient got platelet concentrate transfusion. Laboratory parameter shows that median WBC count was $7.75 \times 109$ / $\mathrm{L}$ and median platelet count was $25 \times 109 / \mathrm{L}$. Among the 40 patients 15 patients (37.5\%) was in DIC (according to the laboratory and clinical data) and 30\% patient got management according to DIC. According to Tallman M. S. et al (1997) among 172 APL patients $52 \%$ had coagulopathy or bleeding. ${ }^{11}$ According to Ribeiro R.C et al (2006) among 132 adult and 16 children with APL obtained from 11 Brazilian centers DIC was noted in $45.9 \%$ of patients. ${ }^{5}$ So in both studies the incidence of DIC was more than our study. Among the 40 patient 30 patients got chemotherapy along with ATRA. Among the 30 patient 5 patients (12.5\%) developed ATRA syndrome and got management accordingly and $2(5 \%)$ patients died due to that. Of the 40 patients early mortality occurs to 10 (25\% of study population). Bleeding was the common cause $(60 \%)$ of mortality, ATRA syndrome and infectious complication each was $20 \%$.

According to Ribeiro R.C et $\mathrm{al}^{5}$, outcome of children's and adults with APL remains comparatively poor in developing countries. For example, selected clinical, laboratory and outcome data of 132 adult and 16 children with 
APL obtained from 11 Brazilian centers. ATRA was used in the management of all this cases. Early death was obtained in $42(28.4 \%)$ cases. Bleeding was the most common cause of mortality (36 cases). ATRA syndrome was reported as the cause of mortality in 11 patients (26.2\%). Infectious complication $(10 \%)$ and unknown causes accounted for the remaining $2 \%$ of early failures. $50 \%$ achieves CR. CR rates ranges from $20 \%$ to $77.0 \%$ among the 11 institutions and all of these outcomes has similarity with the study result that we got in our study.

According to Sanz M A et $\mathrm{al}^{6,7}$, Survey of PATHEMA group showed that about $3 \%$ to $5 \%$ of all patients diagnosed with APL die of hemorrhage before therapy has been started. In our study 6 out of 40 that means $15 \%$ of APL patients died due to bleeding in the presentation period which was definitely more than the developed countries.

So the main cause of treatment failure during the presentation period and remission induction phase was early mortality and in spite of the availability of effective curative treatment protocol a significant proportion of patients could not receive that due to the high early mortality rate.

\section{Conclusion:}

Higher incidence of early mortality is an important cause of treatment failure in the study and which can be reduced by considering APL as a medical emergency, initiation of ATRA as soon as the diagnosis is suspected, proper management of coagulopathy, treatment of ATRA syndrome at the initial stage and proper management of infectious complication etc. So high level of suspicion and early referring of the patients from other centre to haematology department is needed.

\section{References:}

1. Jaffe ES, Harris NL, Stein H et al. Pathology and genetics of Tumours of Haematopoietic and Lymphoid tissues. World Health Organization Classification of Tumour. Lyon; IARC press, 2001: pp 81-87

2. Beaumont M, Sanz M, Carli PM, et al. Therapy related acute promyelocytic leukemia . A report on 106 cases. J Clin Oncol. 2003; 21: 2123-37

3. Lo-Coco F, Ammatuna E. The biology of acute promyelocytic leukemia and its impact on diagnosis and treatment. Hematology Am Soc Hematol Educ Program.2006:156-61

4. Burnett A K. Acute myeloid leukemia in: Hoffbrand VA, Catovky D, Tuddenham GDE. (Eds) Postgraduate Haematology.5th Edition, Oxford, UK. Blackwell Publishing 2005: p. 509-524

5. Riberio RC, Rego E et al. Management of APL in developing countries: epidemiology, challenges and opportunities for international collaboration. Hematology Am Soc Hematol Educ Program. 2006:162-8

6. Sanz MA, Tallman MS, Lo-Coco F. Tricks of the trade for the appropriate management of acute promyelocytic leukemia. Blood. 2005; 105: 301925.

7. Sanz MA, Tallman MS, Lo-Coco F. Practice point, consensus and controversial issues in the management of patients with newly diagnosed acute promyelocytic leukemia. Oncologist.2005;10(10):806-14

8. Arbuthnot C, Wilde JT. Haemostatic problem in acute promyelocytic leukemia. Blood. 2006;20(6):289-97

9. Leukaemia research fund acute myeloid leukemia and high risk MDS trial 14 (online) 2004 Jan 03 [cited 2008 May 14] available from : URL: http:// www.download.bham.ac.uk/bctu/am114/ trial\%20documentation/amendment \%20january \%202004/protocol\% 20Jan202004.pdf

10. Tallman MS, Nabhan $\mathrm{Ch}$, Feusner JH, et al. Acute promyelocytic leukemia: evolving therapeutic strategies. Blood. 2002;99:759-67.

11. Tallman MS, Andersen JW, Schiffer CA, et al. All-trans retinoic acid in acute promyelocytic leukemia. N Engl J Med. 1997;337:1201-8 